\title{
Rapid decline of endemic snails in the Ogasawara Islands, Western Pacific Ocean
}

\author{
Takashi OHbaYashi, ${ }^{1, *}$ Isamu OKOCHI, ${ }^{2}$ Hiroki Sato, ${ }^{2}$ Tsuyoshi Ono ${ }^{1}$ and Satoshi ChIBA ${ }^{3}$ \\ ${ }^{1}$ Agricultural Pest Division, Ogasawara Subtropical Branch of Tokyo Metropolitan Agricultural Experiment Station; Chichijima \\ Island, Ogasawara, Tokyo 100-2101, Japan \\ ${ }^{2}$ Department of Forest Entomology, Forestry and Forest Products Research Institute; Tsukuba, Ibaraki 305-8687, Japan \\ ${ }^{3}$ Biological Institute Graduate School of Science, Tohoku University; Sendai, Miyagi 980-8578, Japan \\ (Received 9 December 2006; Accepted 1 May 2007)
}

\begin{abstract}
The distribution of Mandarina spp., endemic land snails (ground-dowelling ecotype species) of the Ogasawara (Bonin) Islands (Japan), was examined from the 1980's to the present in Chichijima and Hahajima islands. In Chichijima Island, M. mandarina has been rapidly declining since the 1990's in the northeastern area of the island. On the other hand, M. chichijimana has only slightly declined since the 1990's in the southern area of the island. In Hahajima Island since the 1990's, M. polita has slightly declined in the central area while M. ponderosa has been rapidly declining, and M. aureola has shown almost no decline in the southern area of the island. These circumstances offer evidence of the expansion of land snail predators (flatworms). Moreover, Chichijima and Hahajima islands differ in the pace of their respective decline, perhaps because of a predatory flatworm, Platydemus manokwari, used previously as a biological control agent abroad for the giant African snail, Achatina fulica, which only invaded Chichijima Island in the 1990's.
\end{abstract}

Key words: Mandarina spp.; land snail decline; island biology; Platydemus manokwari; Ogasawara (Bonin) Islands

\section{INTRODUCTION}

In tropical oceanic islands, it has been found that many endemic land snails have already become extinct as a result of exotic predators such as the predatory snail, Euglandina rosea or the predatory flatworm, Platydemus manokwari introduced for biological control of the giant African snail, Achatina fulica, or through accidental invasion (Muniappan, 1983, 1987, 1990; Clarke et al., 1984; Muniappan et al., 1986; Takeuchi et al., 1991; Hopper and Smith, 1992; IUCN/SSC Mollusc Specialist Group, 1995; Cowie, 2001a, b; Tomiyama, 2002a; Ohbayashi et al., 2005; Sugiura et al., 2006); however, the process by which extinction occurs is relatively unknown.

The Ogasawara (Bonin) Islands are located in the western Pacific Ocean about $1,000 \mathrm{~km}$ south of the mainland of Japan. More than 100 species of land molluscs have been recorded on the islands, of which 94\% are endemic (Tomiyama and Kurozumi, 1992; Tomiyama, 1994); however, about $40 \%$ of the endemic species are already extinct (Kurozumi, 1988; Tomiyama and Kurozumi, 1992).

The following may be possible reasons for this decline: introduction of exotic snails such as $A$. fulica (Kurozumi, 1988; Tomiyama, 2002a); introduction of the predatory snail E. rosea for the control of A. fulica in 1965 in Chichijima Island (Takeuchi et al., 1991); predation by predatory flatworms distributed before $P$. manokwari invasion (Kawakatsu et al., 1999; Okochi et al., 2004); invasion of the alien predatory flatworm P. manokwari in Chichijima Island in the 1990's (Kawakatsu et al., 1999; Tomiyama, 2002a; Ohbayashi et al., 2005); predation by alien rats (Tomiyama, 2002a); and forest destruction (Tomiyama, 2002a). In Chichijima Island, the most likely cause of the decline of land snails is thought to be the invasion of

* To whom correspondence should be addressed at: E-mail: Takashi_Ohbayashi@member.metro.tokyo.jp DOI: $10.1303 / \mathrm{aez} .2007 .479$ 
P. manokwari in the 1990's (Kawakatsu et al., 1999; Tomiyama, 2002a; Ohbayashi et al., 2005; Sugiura et al., 2006).

One of the endemic genus Mandarina has diversified into taxa occupying many habitats (e.g. arboreal, semi-arboreal, terrestrial, dry, and wet habitats), and shows remarkable diversity in shell and genital morphology (Minato, 1978; Chiba, 1996, 2003); however, Mandarina spp. also has suffered serious destruction due to predation by introduced species such as $P$. manokwari (Chiba, 2003). Thus, understanding the process of the decline of Mandarina spp. and the impact of P. manokwari on Mandarina spp. might useful for the conservation of Mandarina spp. in future.

This study was undertaken to clarify the process of extinction of Mandarina spp. from the 1980's to the present through distribution research, and how P. manokwari, which invaded Chichijima Island in the 1990's, relates to the decline of Mandarina spp. by comparing the process of decline in Chichijima and Hahajima islands.

\section{MATERIALS AND METHODS}

Study areas. All studies were conducted in Chichijima and Hahajima islands, which are part of the Ogasawara (Bonin) Islands (Fig. 1).

Distribution of Mandarina spp. From 1986 to 2003 (covering spring to winter, with search areas and months differing with the year), we searched under fallen leaves, logs and stones in the daytime, and recorded the sites where live ground-dwelling ecotypes Mandarina spp. (M. mandarina, $M$. chichijimana, M. polita, M. aureola and M. ponderosa) were detected every 1 to 5 years. Each site was about $1 \mathrm{~m}^{2}$ in area. Species of Mandarina spp.

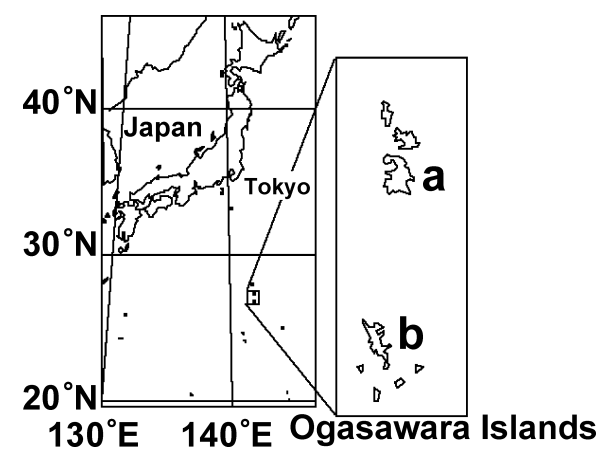

Fig. 1. Location of the Ogasawara Islands. a: Chichijima Island; b: Hahajima Island. were identified according to Chiba (1989, 2003, 2004).

There were 26 research sites in Chichijima Island and 73 sites in Hahajima Island.

Changes in the distribution area of Mandarina spp. According to Tomiyama (2002a), the mobility of Mandarina spp. is very low, so we assumed that the restoration of extinct populations by re-invasion would not occur during the research years. Therefore, we regarded populations at sites where live snails were confirmed to have been in the same location and not migrants from elsewhere. If a population was not confirmed at a site one year but was discovered at the site in a later year, we assumed that its density had been too low to have been detected in the earlier year. According to these assumptions, we made distribution maps for the years 1986, 1995 and 2003.

Distribution of Platydemus manokwari. We searched under stones and logs in the daytime in the years 1995, 1998, 2002, 2003 and 2004 (29 times in total) in Chichijima Island and in the years 1998 and 1999 (5 times in total) in Hahajima Island (covering spring to winter, with search areas and months differing with the year). We also conducted nighttime observations of the forest floor (once in December 1998 and once a month from January to July, 2004 in Chichijima Island and once in January 1999 in Hahajima Island), and recorded the sites where Platydemus manokwari was detected.

We also used $20 \mathrm{~cm} \times 20 \mathrm{~cm}$ mesh bags made of $5 \mathrm{~mm}$ nylon mesh as attractant traps into which one live A. fulca (shell height: over $40 \mathrm{~mm}$ ) was put in Chichijima Island. The traps were set on the forest floor near a road (45 sites) from March to May 1998, checked every few weeks, and the sites where P. manokwari was detected were recorded.

\section{RESULTS}

\section{Distribution of Mandarina mandarina (Chichi- jima Is.)}

Mandarina mandarina was distributed over the northern and northeastern areas of Chichijima Island in 1986 (Fig. 2a). In 1995, the first local extinction occurred at one point in the northern area of Chichijima Island (Fig. 2b). After that, extinction advanced rapidly to the year 2003 in Chichijima Island, so that M. mandarina now only occurs 
a. 1986

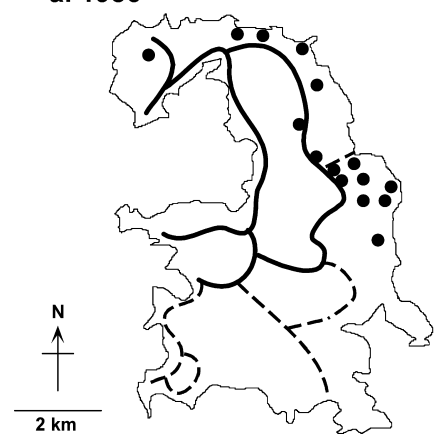

b. 1995

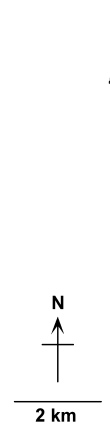

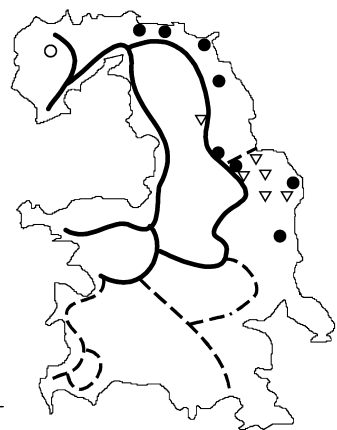

c. 2003

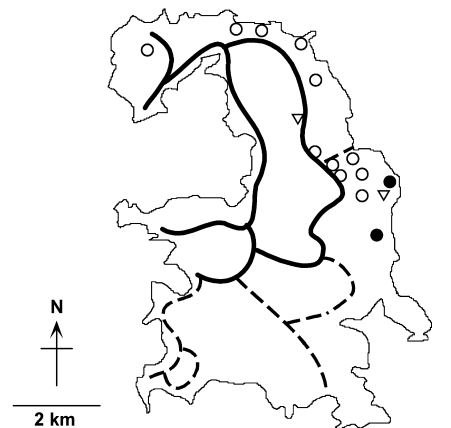

Fig. 2. Distributions of Mandarina mandarina in Chichijima Island in the years 1986 (a), 1995 (b) and 2003 (c). •: Live M. mandarina was recorded; $\bigcirc$ : Live M. mandarina was not recorded; $\nabla$ : Research was not conducted. Solid lines in the maps indicate surfaced roads and broken lines indicate mountain trails.
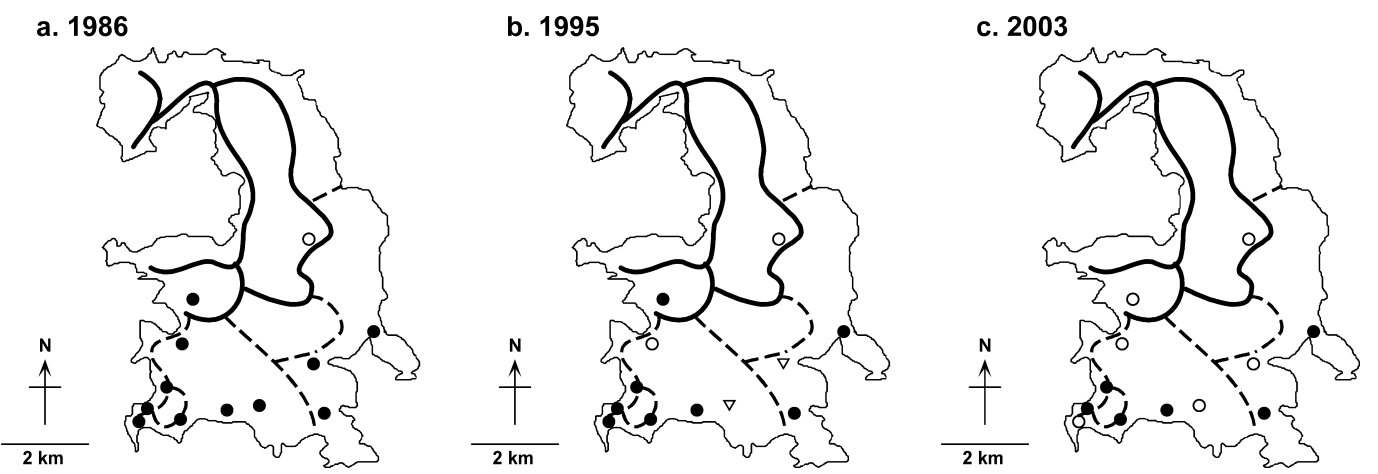

Fig. 3. Distributions of Mandarina chichijimana in Chichijima Island in the years 1986 (a), 1995 (b) and 2003 (c). ๑: Live M. chichijimana was recorded; $\bigcirc$ : Live $M$. chichijimana was not recorded; $\nabla$ : Research was not conducted. Solid lines in the maps indicate surfaced roads and broken lines indicate mountain trails.

in the northeastern area (Fig. 2c).

\section{Distribution of Mandarina chichijimana (Chi- chijima Is.)}

In 1986, Mandarina chichijimana was distributed over the southern area of Chichijima Island, but there was already no live $M$. chichijimana in the central area of the island (Fig. 3a). In 1995, the first local extinction occurred at one point in the southwestern area of Chichijima Island (Fig. 3b). Subsequently, extinction advanced slightly so that by 2003 in Chichijima Island, the distribution area of $M$. chichijimana was limited to the southeastern and southwestern areas (Fig. 3c). The extinction areas of $M$. chichijimana and M. mandarina were sequenced.

\section{Distribution of Mandarina polita (Hahajima Is.)}

In 1986, Mandarina polita was distributed over the northern and central areas of Hahajima Island (Fig. 4a). By 1995, extinctions had occurred at two points of the central area (Fig. 4b). After that, further extinction advanced in the central area to the year 2003 (Fig. 4c). Moreover, another extinction occurred in the northern area, but it was not clear when it had started (Fig. 4c).

\section{Distribution of Mandarina aureola (Hahajima Is.)}

Mandarina aureola is an allopatric species whose distribution area is adjacent to the area of M. polita. This species was distributed over the southern area and one point of the northern area of Hahajima Island in 1986 (Fig. 5a), and no obvious extinction was observed in either 1995 or 2003 (Fig. 5b, c).

\section{Distribution of Mandarina ponderosa (Hahajima Is.)}

Mandarina ponderosa is a sympatric species whose distribution area overlapped the area of $M$. aureola and M. polita. In 1986, this species occurred sporadically over the northern, central and 
a. 1986

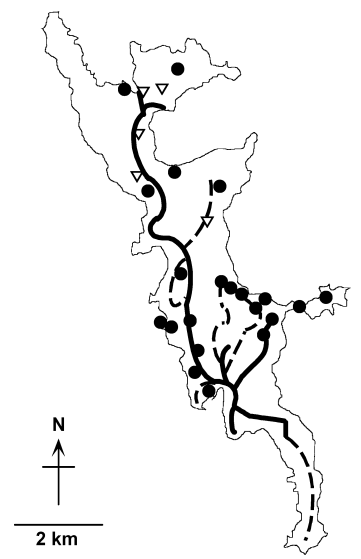

b. 1995

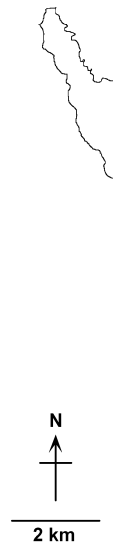

c. 2003

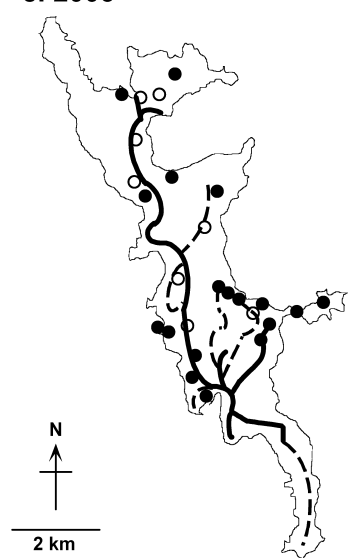

Fig. 4. Distributions of Mandarina polita in Hahajima Island in the years 1986 (a), 1995 (b) and 2003 (c). •: Live M. polita was recorded; $\bigcirc$ : Live M. polita was not recorded; $\nabla$ : Research was not conducted. Solid lines in the maps indicate surfaced roads and broken lines indicate mountain trails.

\section{a. 1986}

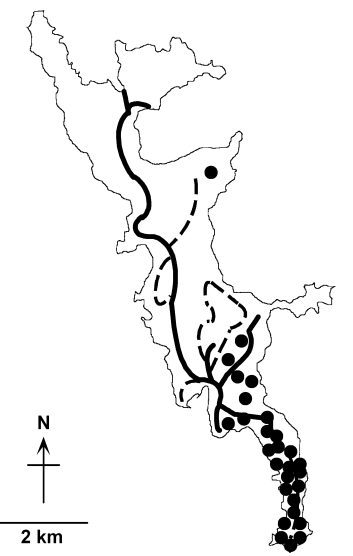

b. 1995

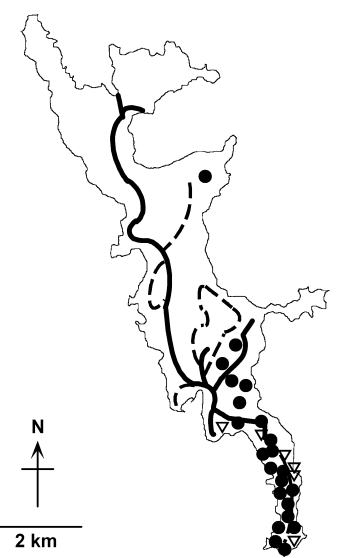

c. 2003

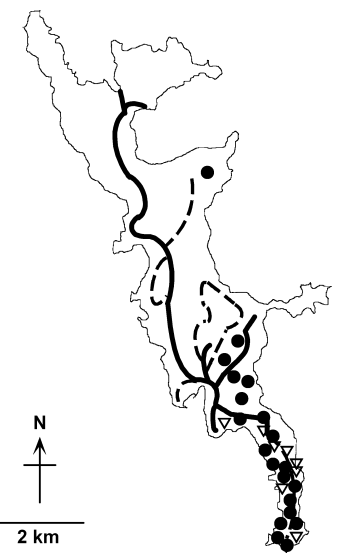

Fig. 5. Distributions of Mandarina aureola in Hahajima Island in the years 1986 (a), 1995 (b) and 2003 (c). •: Live M. aureola was recorded; ○: Live M. aureola was not recorded; $\nabla$ : Research was not conducted. Solid lines in the maps indicate surfaced roads and broken lines indicate mountain trails.

a. 1986

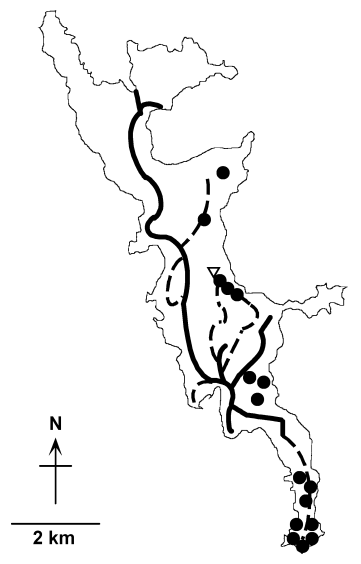

b. 1995

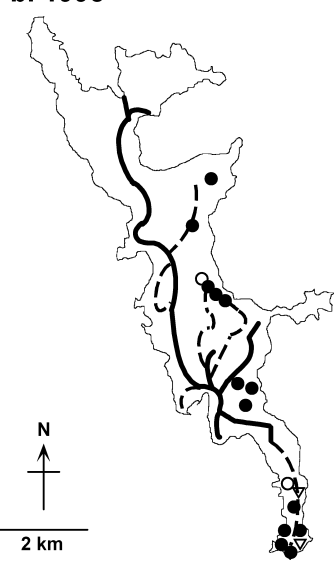

c. 2003

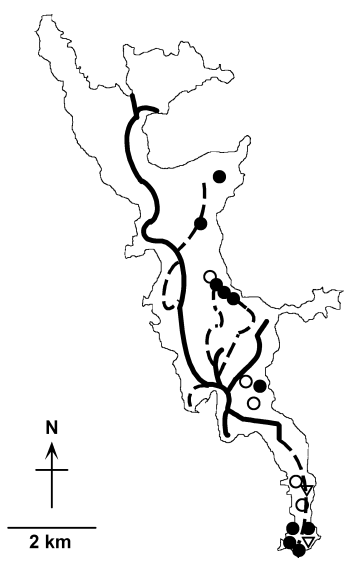

Fig. 6. Distributions of Mandarina ponderosa in Hahajima Island in the years 1986 (a), 1995 (b) and 2003 (c). ๑: Live M. ponderosa was recorded; $\bigcirc$ : Live $M$. ponderosa was not recorded; $\nabla$ : Research was not conducted. Solid lines in the maps indicate surfaced roads and broken lines indicate mountain trails. 

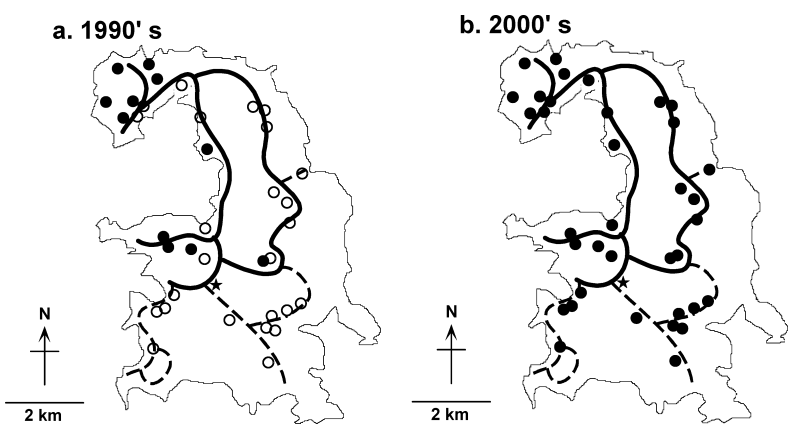

Fig. 7. Distributions of Platydemus manokwari on Chichijima Island in the 1990's (a) and 2000's (b). •: $P$. manokwari was recorded; O: P. manokwari was not recorded; $\star$ : The point where one of the attractant traps was set. Solid lines in the maps indicate surfaced roads and broken lines indicate mountain trails.

southern areas of Hahajima Island (Fig. 6a), but by 1995, there had been a decline in the central and southern areas (Fig. 6b). Further decline had occurred in the southern area by the year 2003 (Fig. $6 c)$.

\section{Distribution of Platydemus manokwari}

In Chichijima Island, Platydemus manokwari was detected near the town (northwest) and farmland (central) areas, and along the road linking these areas in the 1990's (Fig. 7a). In the present decade, P. manokwari has been detected over a wide area of the island (such as the central mountain areas), except for the eastern and southern coastal areas (Fig. 7b).

In nine of the 37 sites where $P$. manokwari was recorded, land snails and $P$. manokwari coexisted, but at the other 28 sites, only $P$. manokwari was recorded, and only one of the 45 traps attracted $P$. manokwari ( $\star$ of Fig. 7).

On the other hand, in Hahajima Island, no $P$. manokwari was detected in any area.

\section{DISCUSSION}

Until the mid 1980's, before Platydemus manokwari invaded Chichijima Island, there were many Mandarina spp. populations in Chichijima (and Hahajima) Island(s) (Kurozumi, 1988 and Figs. 2-6). This suggests that the impact of predators such as Euglandina rosea, introduced in the 1960's to Chichijima Island (Takeuchi et al., 1991) distributed in limited area, was not so serious in those days (Kurozumi, 1988).
However, around 1986 in Chichijima Island, there was already no Mandarina spp. from the northwest coastal area to the south-central area (Figs. 2 and 3). There are many farmlands and roads in these areas which were home to many exotic snails (such as Achatina fulica and Bradybaena similaris), as well as the predatory snail, $E$. rosea (Kurozumi, 1988; Takeuchi et al., 1991; Tomiyama, 1991, 1994). E. rosea is not distributed in Hahajima Island, but except for this point, the conditions on Chichijima Island in the 1980's were similar to those on Hahajima Island at present (Okochi et al., 2004).

In the 1980's, there were several species of predatory flatworms (but not $P$. manokwari) in Chichijima Island (Kawakatsu et al., 1999), so a similar decline caused by alien species and predators may have occurred there, similar to the current situation in Hahajima Island.

In 1995, M. mandarina was extinct in one of the northern areas of Chichijima Island (Fig. 2b). There were already E. rosea (Kurozumi, 1988) and several predatory flatworms (but not $P$. manokwari) in this area (Kawakatsu et al., 1999), so these predators affected M. mandarina in the 1980's, and subsequently in the 1990 's, the invasion of P. manokwari might have been the final blow for $M$. mandarina. Incidentally, this point is thought to be where P. manokwari began its invasion (Fig. 7).

On the other hand, one extinct area of $M$. chichijimana population in the southwestern area of Chichijima Island in 1995 (Fig. 3b) was far from the first area invaded by P. manokwari, but recently, $P$. manokwari has been recorded in the vicinity (Fig. 7b). Consequently, this extinction is thought to have been caused by P. manokwari.

The expansion of extinct areas during the eight years from 1995 to 2003 has been startling (Figs. 2 and 3). P. manokwari occurred in those areas (Fig. $7 \mathrm{~b}$ ), so it is believed to be the cause of decline. This sudden expansion might have been caused by artificial transmission by human activities, and the abundant supply of exotic land snails as food sources. So it is likely that $M$. chichijimana, as the endemic species of Chichijima Island, might become extinct some time in the future.

In Hahajima Island, M. polita has slightly declined (Fig. 4). This decline was thought to have been caused by predation by flatworms (Kawakatsu et al., 1999) which have increased their population 
by preying upon, and winning competition against, exotic land snails such as A. fulica (Okochi et al., 2004). The extinction areas were concentrated along surfaced roads from north to south on Hahajima Island and the mountain trail in the central part of the island. According to Numazawa et al. (1988), the exotic land snail A. fulica preferred disturbed areas affected by human impact. Furthermore, Okochi et al. (2004) described that predators such as $P$. manokwari can readily be transported by human activities, so disturbance caused by the construction of these roads has led to the invasion of exotic land snails and predators and, as a result, extinction areas might be increasing.

Meanwhile, M. aureola, which is distributed in the southern area of Hahajima Island, was thought to be safe from extinction (Fig. 5); however, a surfaced road was constructed in the southern area of Hahajima Island recently, but exotic land snails are still rare there (Okochi et al., 2004), so M. aureola is surviving.

M. ponderosa has declined in the central and, especially, southern areas of Hahajima Island (Fig. 6), but the reason for its decline is thought to be different from that of $M$. polita. They are all ground-dwelling ecotypes (Chiba, 2003), so they compete against each other; therefore, extinction may occur if their populations are decreased by environmental deterioration. Except for one northern area where $M$. ponderosa has survived and $M$. polita is extinct, $M$. ponderosa is competitively inferior to M. polita and M. aureola.

These findings reveal that the respective processes of extinction of Mandarina spp. in Chichijima and Hahajima islands are very different (Figs. 2-6), as is the distribution of P. manokwari in the two islands (Fig. 7). In other words, the invasion of $P$. manokwari has caused a rapid decline in land snails; if the invasion of $P$. manokwari had not occurred, the decline might have been slow. Indeed, Sugiura et al. (2006) confirmed that P. manokwari puts high predation pressure on land snails in Chichijima Island.

The invasion of $P$. manokwari is rapidly bringing about the extinction of Mandarina spp. in the oceanic Ogasawara Islands because ecological resistance against the invasion of $P$. manokwari there might be weak. Moreover, the expansion of $P$. manokwari might be very rapid in disturbed areas (Fig. 7). It thus might be very difficult to eradicate
P. manokwari that has already invaded Chichijima Island (Tomiyama, 2002b), so it is necessary to take immediate steps to preserve the populations of endemic species, M. chichijimana. For this purpose, populations must be isolated from predators, or introduced (or re-introduced) to outlying islands where no Mandarina spp. occur (if possible, to islands where land snails were distributed previously).

Moreover, it is necessary to make all possible efforts to prevent $P$. manokwari from invading Hahajima Island as well as uninhabited islands surrounding Chichijima and Hahajima islands. However, since a large amount of materials are moved between Chichijima Island and Hahajima Island, it will be necessary to restrict the transfer of plant seedlings and cars that have soil adhering to them. In addition, efforts should be made to keep uninhabited islands such as Anijima Island isolated.

$P$. manokwari is vulnerable to low temperature (Kaneda et al., 1992) and seawater (Ohbayashi, unpublished), so to prevent it from invading these uninhabited islands, shoes ought to be sterilized using refrigeration or seawater.

Incidentally, in Hahajima Island, which has currently not been invaded by $P$. manokwari, extinction by alien species and predatory flatworms has occurred in disturbed areas such as road construction sites; however, it is notable that extinction has also occurred at Mt. Chibusa in the central area, where only mountain trails have been constructed (Figs. 4 and 6). So in areas where many endemic land snails still survive, the construction of mountain trails should be reconsidered, and if possible, these areas should be managed to avoid disturbing endemic snail habitats.

\section{ACKNOWLEDGEMENTS}

We thank Dr. Masaharu Kawakatsu, Dr. Kiyonori Tomiyama of Kagoshima University, Mr. Nathaniel Savory Jr., Mr. Koji Takeuchi, and Dr. Kikuo Iwabuchi of Tokyo University of Agriculture and Technology for their helpful advice. We also thank Ms. Fumiko Yumura (Shibazaki), Ms. Yukari NiikawaSeimiya, Ms. Noriko Saito-Karashima, and Ms. Nobuko Ono for their help with the field surveys. This study was partially funded by the Ministry of the Environment of Japan.

\section{REFERENCES}

Chiba, S. (1989) Taxonomy and morphologic diversity of Mandarina (Pulmonata) in the Bonin Islands. Trans. Proc. Palaeont. Soc. Jpn. N. S. 155: 218-251.

Chiba, S. (1996) Ecological and morphological diversifica- 
tion and character displacement in Mandarina, an endemic land snail of the Bonin Islands. J. Evol. Biol. 9: $277-291$.

Chiba, S. (2003) Species diversity and conservation of Mandarina, an endemic land snail of the Ogasawara Islands. Global Environ. Res. 7: 29-37.

Chiba, S. (2004) Ecological and morphological patterns in communities of land snails of the genus Mandarina from the Bonin Islands. J. Evol. Biol. 17: 131-143.

Clarke, B., J. Murray and M. S. Johnson (1984) The extinction of endemic species by a program of biological control. Pacific Sci. 38: 97-104.

Cowie, R. H. (2001a) Extinction or survival: partulid tree snails in American Samoa. Biodivers. Conserv. 10: 143-159.

Cowie, R. H. (2001b) Decline and homogenization of Pacific faunas: the land snails of American Samoa. Biol. Conserv. 99: 207-222.

Hopper, D. R. and B. D. Smith (1992) Status of tree snails (Gastropoda: Partulidae) on Guam, with a resurvey of sites studied by H. E. Crampton in 1920. Pacific Sci. 46: 77-85.

IUCN/SSC Mollusc Specialist Group (1995) Statement of concern and summary of recommendations. Tentacle 5: 13.

Kaneda, M., K. Kitagawa, H. Nagai and F. Ichinohe (1992) The effects of temperature and prey species on the development and fecundity of Platydemus manokwari De Beauchamp (Tricladida: Terricola: Rhynchodemidae). Res. Bull. Pl. Prot. Jpn. 28: 7-11.

Kawakatsu, M., I. Okochi, H. Sato, T. Ohbayashi, K. Kitagawa and K. Totani (1999) A preliminary report on land planarians (Tubellaria, Seriata, Tricladida, Terricola) and land nemertine (Enopla, Hoplonemertea, Monostylifera) from the Ogasawara Islands. Occasional Publications, Biological Laboratory of Fuji Women's College, Sapporo (Hokkaido), Japan 32: 1-8.

Kurozumi, T. (1988) Species composition and abundance of land mollusks and factors affecting their extinction in the Ogasawara (Bonin) Islands. Ogasawara Res. 15: 59109 (in Japanese with English summary).

Minato, H. (1978) Speciation of the genus Mandarina from the Ogasawara Islands (Pulmonata, Camaenidae). Mem. Nat. Sci. Mus. Tokyo 11: 37-51 (in Japanese with English summary).

Muniappan, R. (1983) Biological control of the giant African snail. Alafua Agric. Bull. 8: 43-46.

Muniappan, R. (1987) Biological control of the giant African snail Achatina fulica Bowdich, in the Maldives. F. A. O. Plant Protect. Bull. 35: 127-133.
Muniappan, R. (1990) Use of the planarian, Platydemus manokwari, and other natural enemies to control the giant African snail. In The Use of Natural Enemies to Control Agricultural Pests. FFTC Book Series No. 40 (O. Mochida and K. Kiritani eds.). Food and Fertilizer Technology Center for the Asian and Pacific Region, Taipei, pp. 179-183.

Muniappan, R., G. Duhamel, R. M. Santiago and D. R. Acay (1986) Giant African snail control in Bugsuk Island, Philippines, by Platydemus manokwari. Oléagineux 41: $183-186$.

Numazawa, K., S. Koyano, N. Takeda and H. Takayanagi (1988) Distribution and abundance of the Giant African snail, Achatina fulica Férussac (Pulmonata: Achatinidae), in two islands, Chichijima and Hahajima, of the Ogasawara (Bonin) Islands. Jpn. J. Appl. Entomol. Zool. 32: 176-181 (in Japanese with English summary).

Ohbayashi, T., I. Okochi, H. Sato and T. Ono (2005) Food habit of Platydemus manokwari De Beauchamp, 1962 (Tricladida: Terricola: Rhynchodemidae), known as a predatory flatworm of land snails in the Ogasawara (Bonin) Islands, Japan. Appl. Entomol. Zool. 40: 609-614.

Okochi, I., H. Sato and T. Ohbayashi (2004) The cause of mollusk decline in the Ogasawara Islands. Biodivers. Conserv. 13: 1465-1475.

Sugiura, S., I. Okochi and H. Tamada (2006) High predation pressure by an introduced flatworm on land snails on the oceanic Ogasawara Islands. Biotropica 38: 700-703.

Takeuchi, K., S. Koyano and K. Numazawa (1991) Occurrence of the giant African snail in the Ogasawara (Bonin) Islands, Japan. Micronesia Suppl. 3: 109-116.

Tomiyama, K. (1991) Terrestrial molluscan fauna of Chichijima Islands, the Ogasawara Islands, with special reference to Ani-jima island. Ogasawara Res. 17/18: 1-31 (in Japanese with English summary).

Tomiyama, K. (1994) Factors affecting the extinction of land snails on the Ogasawara Islands. Venus 53: 152-156 (in Japanese, title translated by the author).

Tomiyama, K. (2002a) Land mollusks of the Ogasawara Islands - the weakness of Oceanic island species. Shinrin Kagaku 34: 25-28 (in Japanese, title translated by the author).

Tomiyama, K. (2002b) Euglandina rosea. In Handbook of Alien Species in Japan (The Ecological Society of Japan ed.). Chijin-Shokan, Tokyo, p. 166 (in Japanese).

Tomiyama, K. and T. Kurozumi (1992) Terrestrial mollusks and conservation of their environment in the Ogasawara Islands. Regional Views 5: 39-81 (in Japanese with English summary). 